\title{
Nanolamellar Tantalum Interfaces in the Osteoblast
}

\section{Adhesion}

Rong An, ${ }^{* \dagger}$ Peng Peng Fan, ${ }^{\dagger}$ Ming Jun Zhou, ${ }^{\ddagger}$ Yue Wang, ${ }^{\dagger, \S}$ Sunkulp Goel, ${ }^{\dagger}$ Xue Feng Zhou, ${ }^{*}$, Wei Li, ${ }^{\|}$Jing Tao Wang $*, \dagger$

${ }^{\dagger}$ Herbert Gleiter Institute of Nanoscience, Nanjing University of Science and Technology, Nanjing 210094, P.R. China

$\$$ State Key Laboratory of Bioelectronics, Jiangsu Key Laboratory for Biomaterials and Devices, School of Biological Science and Medical Engineering, Southeast University, Nanjing 210096, P.R. China

${ }^{\S}$ Xiamen Golden Egret Special Alloy Co., LTD, Xiamen 361021, P.R. China

" European Bioenergy Research Institute, Aston Institute of Materials Research, Aston University, Birmingham, B4 7ET, UK

ABSTRACT: The design of topographically patterned surfaces is considered to be a preferable approach to influence cellular behavior in a controllable manner, in particular to improve the osteogenic ability in bone regeneration. In the present study, we fabricated nanolamellar tantalum (Ta) surfaces with lamella wall thicknesses of $40 \mathrm{~nm}$ and $70 \mathrm{~nm}$. The cells attached onto nanolamellar Ta surfaces exhibited higher protein adsorption and expression of $\beta 1$ integrin, as compared to the non-structured bulk Ta, which would facilitate the initial cell attachment and spreading. We thus as expected, observed a significantly enhanced osteoblast adhesion, growth, and alkaline phosphatase activity on nanolamellar Ta surfaces. However, the enhancement effects 
of nanolamellar structures on the osteogenesis were weakened as the lamella wall thickness increases. The interaction between cells and Ta surfaces is examined through adhesion forces using atomic force microscopy. Our findings indicate that Ta surface with a lamella wall thickness of 40 $\mathrm{nm}$ possessed the highest stimulatory effect. The observed strongest adhesion force between cellattached tip and the Ta surface with $40 \mathrm{~nm}$-thick lamella wall, encourages the much stronger binding of cells with the surface, and thus well- attached, stretched, and grown cells. We attributed this to the increase in available contact area of cells with the thinner-nanolamellar Ta surface. The increased contact area allows the enhancement of the cell-surface interaction strength, and thus the improved osteoblast adhesion. This study suggests that the thin-nanolamellar topography shows immense potential in improving the clinical performance of dental and orthopedic implants.

\section{INTRODUCTION}

Dental and orthopedic implants are hard tissue substitutes for impaired human bones in case of tumors, trauma, periodontal diseases and aging. Effective osteogenic reconstruction of bone lost is therefore becoming a major challenge. ${ }^{1,2}$ Bone reconstruction generally requires fabrication of biocompatible and osteoinductive artificial tissue implants, which act as a temporary matrix for cell proliferation, osteogenic differentiation, and extracellular matrix deposition with consequent bone growth until the new bone tissue is fully formed. ${ }^{3}$

An early bone formation and strong binding between bone and implant are important for the long-term success of the orthopedic implants. ${ }^{4}$ It is noting that cells approaching a surface from a flowing carrier fluid, in many biomedical applications, will be attracted by the substratum surface

with adhesion forces generated by the transport of biomolecules towards a surface. ${ }^{5,6}$ High adhesive characteristics of the implant substrate to osteogenic cells, is thus crucial for the cells' capacity to proliferate and differentiate themselves on contact with the implant. ${ }^{2,7-9}$ The interaction 
of cells with the surface depends on the surface topographical feature and chemical composition. $^{3,10-12}$ Tantalum (Ta) is an elemental metal that has recently gained interests for a variety of applications in orthopedic implant contexts, ${ }^{7,12,13}$ because of the excellent corrosion resistance and exceptional biocompatibility, as well as the lower bacterial adherence, in comparison with titanium and stainless steel implants. ${ }^{14,15}$ To enhance the fixation between the Ta implant and bone, previous studies have focused on the modulation of cell-implant interactions by manipulating surface chemical compositions and topographical features.

One feature influencing cell-implant interactions is the chemical composition of implant materials. Among the various surface modification techniques, the scaffolds surface treatment with natural materials, e.g., collagen, chitosan, $\mathrm{N}$-succinyl-chitosan, used for tissue-engineered bonerepair techniques is expected to increase osteoblast adhesion. ${ }^{16} \mathrm{TiO}_{2}$ nanotubular implants modified by Ta coatings could enhance alkaline phosphatase activity, and promote a $\sim 30 \%$ faster rate of matrix mineralization and bone-nodule formation. This enhanced activity and bone regeneration were attributed to distinctive physico-chemical properties induced by Ta surface chemistry and $\mathrm{TiO}_{2}$ architecture. ${ }^{17}$ A porous Ta surface with micro-arc oxidation and alkali treatment, formed an apatite layer after being soaked in simulated body fluid. On this modified porous Ta surface with $\mathrm{NaOH}$ pretreatment, the cell toxicity of the leach liquor can be eliminated and new bone ingrowth would be promoted. ${ }^{13}$ Additionally, surface modification by anodic oxidation was designed to enhance osseointegration of metal implants for anchorage of dental prostheses, hip arthroplasty femoral stems, and so on. ${ }^{18,19}$ Unfortunately, unexpected side effects are possible when using chemical strategies upon the bio-surfaces, such as weakening biomolecular responses, ${ }^{20}$ and enhanced susceptibility to biochemically relevant solutions. ${ }^{21,22}$

The favorable physical strategy has fewer side effects on the surrounding environment. The 
topographical design of implant surfaces has a significant influence on fundamental cell behavior including proliferation and osseointegration via enhancing the cell-implant interactions. ${ }^{2,8,11,23}$ Because surface micro-/nano-structures could maximize cell ingrowth and tissue integration by enhancing the cell-implant interactions during the implanting process. ${ }^{11,24}$ For example, Ta implants with a nanostructured surface (feature height $<5 \mathrm{~nm}$ ), are able to influence cell-Ta interactions and thus the cell adhesion and proliferation. ${ }^{11}$ Hydroxyapatite bioceramics with hierarchical micro/nano- hybrid surface topographies via hydrothermal treatment, were found to result in the best ability for simultaneous enhancement of protein adsorption, osteoblast proliferation, and differentiation. ${ }^{3}$ Highly ordered, nanostructured Ta implants were fabricated using colloidal lithography and glancing angle deposition techniques to modulate cell-implant interactions, to further control adhesion, growth, and differentiation of human mesenchymal stem cells. ${ }^{25}$ Nanocrystalline surface layers with extremely small grains (average grain size of $\leqslant 20 \mathrm{~nm}$ ) were fabricated on pure Ta. And the resulting drastically increased numbers of grain boundaries exhibited considerably enhanced osteogenic activity. ${ }^{26}$ Porous Ta was found to be able to promote enhanced biological fixation ${ }^{27,28}$ by enhancing in vitro cell-implant interactions, attributable to surface chemistry, high wettability ${ }^{28}$ and greater surface energy ${ }^{29}$ provided by porous structures.

Typically, scaffolds consisting of aligned polymeric fibers were found to be osteoinductive, and be able to guide cell growth along the circumferential direction of the parallel fibers. ${ }^{2,30-32}$ It was reported previously that a multi-level lamellar structure ${ }^{33,34}$ consisting of unidirectional micro/macro-pores can support osteoblast attachment and spreading and thus promote the bone tissue regeneration. ${ }^{34}$ An oriented substrate can yield enhanced adhesion and growth of cells, e.g., uniformly aligned structures were able to direct and enhance the osteogenesis., ${ }^{2,34}$

In a parallel to polymeric fibers which exhibit positive effects on osteogenesis, we investigate 
in this work, the cellular effects of nano-topographical features in the form of nanolamellas created on Ta surface by rolling the bulk ultrafine grained Ta. Equal channel angular pressing (ECAP) is one of the most promising techniques in severe plastic deformation, to produce ultrafine grained materials (including our bulk Ta), in which a sample is pressed through a die with two columned channels intersecting at an angle of $90^{\circ} .{ }^{35}$ The cross-sectional dimensions remain unchanged with high dislocation density in the pressing operation, so it is possible to undertake repetitive pressings for a number of passes in order to achieve high cumulative strains. The dislocations are able to rearrange and result in grain sizes in the submicrometer range of $100-1000 \mathrm{~nm}$ or in the nanometer range of $<100 \mathrm{~nm},{ }^{36}$ which are well known as ultrafine grained materials.

The deformation at low temperature, can result in a high density of defects, which could act as potential recrystallization $\operatorname{sites}^{37}$ to produce nanostructures. As a consequence, cryogenic deformation has been successfully employed to produce nanostructured materials and enable further decrease in the size of nanostructures. ${ }^{38}$ In our work, we thus rolled our bulk ultrafine grained $\mathrm{Ta}(\mathrm{B})$ at cryogenic temperature with liquid nitrogen cooling, to obtain nanolamellar $\mathrm{Ta}$ with a lamella wall thickness of $\sim 40 \mathrm{~nm}$ (Ta40). We performed rolling process at room temperature to deform $\mathrm{Ta}(\mathrm{B})$, to obtain nanolamellar Ta with a thicker lamella wall thickness of $\sim 70 \mathrm{~nm}(\mathrm{Ta} 70)$.

Atomic force microscopy (AFM) was employed to examine adhesion forces between cells and nanolamellar Ta, to permit the nanoscale understanding in the effect of the cell-Ta interaction strength on the osteoblast adhesion, proliferation and differentiation. The osteogenic properties of the nanolamellar Ta, as well as cell-Ta interactive strengths would be analyzed systematically using mouse osteoblastic cells, MC3T3-E1 subclone 14.

\section{EXPERIMENTAL SECTION}


Preparation of nanolamellar tantalum. Our ECAP experiments were performed up to 8 passes with route $\mathrm{Bc}$, in which the sample were rotated about their longitudinal axes by $90^{\circ}$ in the same direction between each pass. The grain size of Ta in our work was refined to $\sim 500 \mathrm{~nm}$ by ECAP, and we defined the resultant porosity-free Ta as "bulk ultrafine grained Ta(B)" (see the TEM image shown later in Figure 1a). As shown in Scheme 1a, the ECAP processed bulk Ta(B) samples were rolled from $12 \mathrm{~mm}$ to $2 \mathrm{~mm}$ strips, at cryogenic temperature with liquid nitrogen cooling by two-roller mills with a diameter of $300 \mathrm{~mm}$ at a speed of $15 \mathrm{~m} / \mathrm{min}$. We performed rolling process at room temperature to deform $\mathrm{Ta}(\mathrm{B})$, to obtain nanolamellar $\mathrm{Ta}$ with a thicker lamella wall thickness of $\sim 70 \mathrm{~nm}$ (Ta70).

Here we defined three directions after rolling, rolling direction (RD), transverse direction (TD) and normal direction (ND). The nanolamellar structures can be observed in the cross sectional surfaces of the sample, e.g., RDS and TDS, as illustrated in Scheme 1(b), where RDS and TDS represent the surfaces normal to the rolling and transverse direction respectively. The rolling process at different cooling temperatures formed different thicknesses of nanolamellas that lie parallel to the sample surface (the surface normal to the normal direction, NDS). Electron backscatter diffraction (EBSD) ${ }^{39}$ orientation maps of in Figure S1 confirmed the rolling of bulk Ta could result in the formation of textured nanolamellar Ta with lamellas oriented in the direction of rolling. 


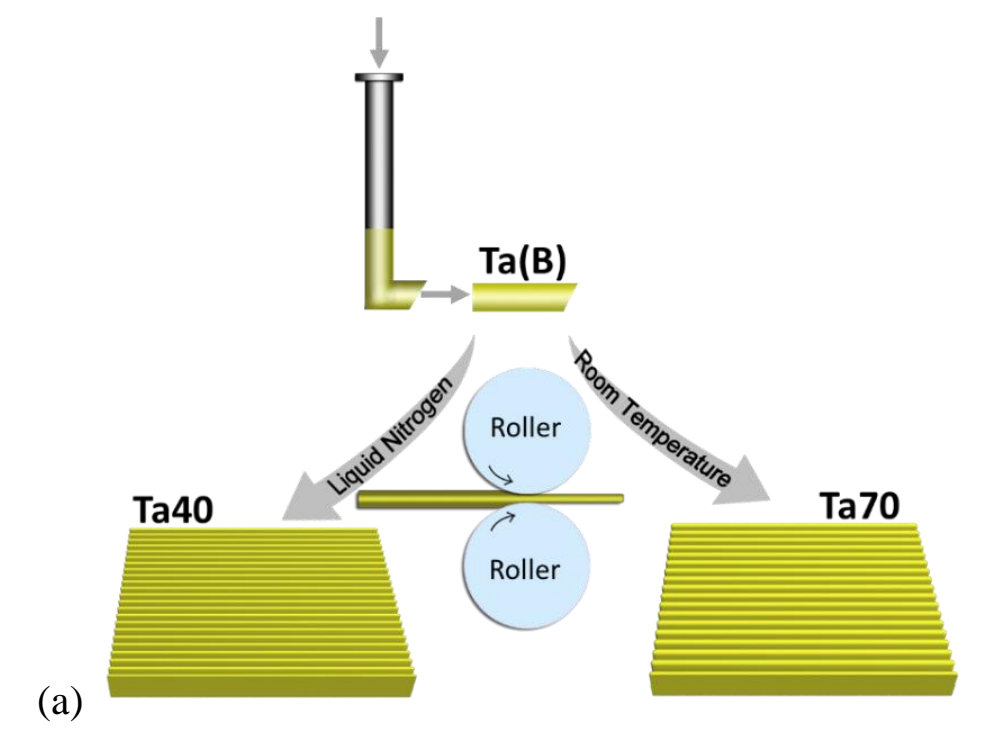

(b)

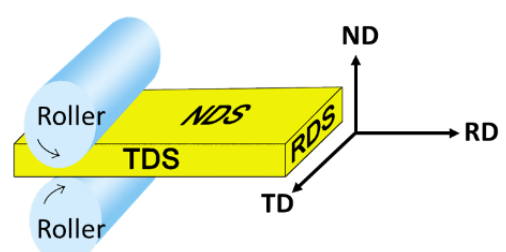

Scheme 1. Schematic illustration of (a) preparation of bulk and nanolamellar Ta (Ta(B), and Ta40, Ta70), (b) The dimension of the rolling Ta sample: RDS, TDS, NDS corresponding to the surfaces normal to the rolling, transverse and normal direction respectively. The nanolamellar structures can be observed in the cross sectional surfaces of the sample, e.g., RDS and TDS.

It is noteworthy that surface damages of the as-prepared bulk and nanolamellar Ta samples need to be removed during subsequent mechanical grinding and polishing. Swab etching (Lactic Acid:HNO $3: \mathrm{HF}=3: 1: 1$ in volume ratio) is further required as a chemical polish to make nanolamellar structures exposed for growing cells. The Ta surfaces were then ultrasonically cleaned in acetone (10 mins)-ethanol (10 mins), and this ultrasonic cleaning was repeated up to 3 times, followed by high-quality deionized (DI) water cleaning for another 10 mins.

Surface characterization. The tantalum morphology was evaluated by atomic force microscopy (AFM, Dimension Icon, Bruker, USA). The microstructure was observed by transmission electron microscopy (TEM, FEI, USA) using a TECNAI G2 20 LaB6 transmission electron microscope. Ta foil samples for TEM characterizations were prepared by a twin jet electropolishing technique. The technique employs a disk electrode (thickness $=0.1 \mathrm{~mm}$, diameter 
$=3 \mathrm{~mm}$ ), with an electrolytic solution consisting of $12.5 \mathrm{vol} \% \mathrm{H}_{2} \mathrm{SO}_{4}$ and $87.5 \mathrm{vol} \% \mathrm{CH}_{3} \mathrm{OH}$ (applied voltage $=26 \mathrm{~V}$, current $=100 \mathrm{~mA})$ at $-30^{\circ} \mathrm{C}$. The crystal phase of tantalum samples was determined by powder X-ray diffraction (XRD, Cu Ka radiation, Bruker D8, USA). Static contact angle measurements were performed via a contact angle meter (JC2000D2, Shanghai Zhongchen Digital Technic Apparatus Co. Ltd., China) using a sessile drop technique. At three different locations, a $0.3 \mu \mathrm{L}$ water droplet was dispensed on the substrate to measure the static contact angle. Here our sample is small, $\sim 2 \mathrm{~mm}$ in width, so that we employed a small water droplet.

Cell culture, adhesion and proliferation. Pure cell culture without our tantalum samples acted as the blank control. The mouse osteoblastic cells, MC3T3-E1 subclone 14, were purchased from the Cell Bank of the Chinese Science Academy (Shanghai, China). The culture medium was supplemented with $10 \%$ fetal bovine serum (Hyclone), $1 \%$ streptomycin, and $1 \%$ penicillin (Beyotime, Shanghai, China) to make osteogenic medium. The MC3T3-E1 cells were cultured in at a humidified atmosphere of $95 \%$ air and $5 \% \mathrm{CO}_{2}$ at $37{ }^{\circ} \mathrm{C}$. Adherent cells were passaged at confluency of approximately $80 \%$. Cells below passage 10 were used in our experiments.

For proliferation examination, the cells were seeded in a 96-well plate at a density of $10^{4}$ cells/well and cultured in the MC3T3-E1 growth medium. At day 1,3,5, and 7, the cell viability was measured using cell counting kit-8 (CCK-8, Beyotime, Shanghai, China) according to the manufacturer's instructions. The optical density (OD) at $450 \mathrm{~nm}$ was measured by an enzymelinked immunosorbent assay plate reader (Titertek, Helsinki, Finland).

Alkaline phosphatase (ALP) activity assay. The level of ALP activity was assayed by measuring the transformation of p-nitrophenyl-phosphate (pNPP: Sigma, St. Louis, USA) into pnitrophenol (pNP) after cell culture at $8 \times 10^{4}$ cells/sample in osteogenic medium in 6 -well plates for 7 and 14 days. ALP activity was determined by measuring absorbance at $405 \mathrm{~nm}$ using pNPP as the substrate. Each sample was respectively mixed with $1 \mathrm{mg} / \mathrm{mL}$ pNPP in $1 \mathrm{M}$ diethanolamine 
buffer and incubated at $37{ }^{\circ} \mathrm{C}$ for 15 min to allow cell attachment. The ALP activity was expressed as absorbance at $405 \mathrm{~nm}$ per milligram of total cellular proteins. All experiments were performed in triplicate.

Statistical analysis. Quantitative data were expressed as means \pm standard deviation (SD). Statistically significant differences (p) between groups were measured using the one-way analysis of the variance and Tukey's multiple comparison tests. The difference were considered statistically significant at $\mathrm{p}<0.05$.

Cell morphology and distribution. Cell morphology of adhesion and spreading was observed and analyzed after culturing for 24 hours. The cell grown Ta specimens were carefully taken out, rinsed with $0.05 \mathrm{M}$ PBS ( $\mathrm{pH}=7.4)$ solution for three times in order to eliminate the loosely bound cells and stored at $4{ }^{\circ} \mathrm{C}$. Noting that the samples need to be analyzed within 2 days to insure cells still present on the surfaces. To evaluate the cell morphology and distribution by SEM, the samples were fixed in glutaraldehyde $(2.5 \%)$ for 12 hours at $4{ }^{\circ} \mathrm{C}$, washed with PBS solution ( $0.05 \mathrm{M}, \mathrm{pH}=7.4)$, dehydrated in sequence by $25,50,75,100$ vol \% ethanol solution buffered by PBS (0.05 M, pH=7.4) for 10 mins, and finally air-dried.

The morphologies of cells adhered to the Ta surfaces were visualized with the confocal laser scanning microscopy (CLSM; Zeiss-LSM710; Carl Zeiss, Inc., Jena, Germany) after 24 h culture. The cells were seeded in a 24 -well plate at a density of $2 \times 10^{4}$ cells/well in triplicate. Before CLSM imaging, the samples were washed with PBS and fixed with $3.7 \%$ paraformaldehyde for $30 \mathrm{~min}$ at room temperature, then permeated in $0.25 \%$ Triton $\mathrm{X}-100 / \mathrm{PBS}$ for $3 \mathrm{~min}$, and sequentially blocked with $3 \%$ bovine serum albumin for $30 \mathrm{~min}$. Following overnight incubation with the rabbit anti-integrin $\beta 1$ antibody ( $\beta 1$, Abcamplc; $1: 100$ dilution) at $4{ }^{\circ} \mathrm{C}$, the samples were rinsed five times with PBS-Tween. Then cells were incubated with rhodamine phalloidin (1:200 
dilution; Cytoskeleton, Inc., Denver, CO, USA) for 30 min and rinsed six times with PBS. After incubation with 4',6-diamidino-2-phenylindole (DAPI, 1:2000 dilution, Beyotime) for $30 \mathrm{~s}$ in the dark at room temperature, samples were rinsed three times with PBS and observed by CLSM.

Protein Adsorption. The fluorochrome labeling protein bovine serum albumin (BSA) was purchased from Solarbio life sciences (Beijing, China). The respective Ta samples were immersed in the mixed solution containing 50\% BSA and 50\% PBS solution for protein adsorption. After protein adsorption, the Ta substrates were washed with PBS, and observed by CLSM.

Adhesion forces between MC3T3-E1 cells and Ta surfaces. Adhesion force measurements were performed on a Dimension Icon AFM in contact mode at room temperature with a relative humidity of $\sim 50 \%$ to avoid the influence of capillary condensation of water, and the attachment of suspended particulates to the tip. ${ }^{40}$ NSC35 tipless probes with $\mathrm{Cr}$-Au coated cantilevers (A cantilever, spring constant of $8.9 \mathrm{~N} / \mathrm{m}$, Mikromasch, USA) were cultured in the osteogenic medium for 24 hours, and the cell attached tips were used for AFM force measurements immediately after preparation. It was observed that for a given sample the force data obtained under these conditions were stable and reproducible. The adhesion forces were measured using the force-distance curve approach, between a cell attached tip and the bare surface. 100 force-distance curves at the maximal adhesion force upon retraction were recorded at multiple randomly chosen spots and analyzed.

\section{RESULTS AND DISCUSSION}


Surface characterization of bulk and nanolamellar Ta. TEM was used here to assess the microstructure, texture as well as grain orientations of bulk and naolamellar Ta in a non-destructive manner. As shown in Figure 1(a), we observed significant morphological differences between bulk 'Ta(B)', and nanolamellar 'Ta40’, 'Ta70'. Bulk Ta surfaces displayed sub-micro-structural grains with a grain size of $\sim 500 \mathrm{~nm})$, which we defined as bulk ultrafine grained Ta(B). However, after subsequent rolling in liquid $\mathrm{N}_{2}$ environment, the microstructures of $\mathrm{Ta}(\mathrm{B})$ were elongated with an average lamella wall thickness of $\sim 40 \mathrm{~nm}$, i.e., Ta40. Thicker lamella wall thickness of $\sim 70 \mathrm{~nm}$ (Ta70) were obtained through performing rolling process on bulk $\mathrm{Ta}(\mathrm{B})$ at room temperature. The TEM micrographs here clearly reveal that the nanolamellar structures in Ta40 and Ta70, with variations in lamella wall thicknesses which are marked as 40, $70 \mathrm{~nm}$ respectively in Figure 1(a). The nanolamellar structures observed in Ta40 and Ta70, were further evidenced by AFM studies. In Figure 1(b), thin-flat nanolamellar interfaces were revealed in Ta40, whereas thick nanolamellas in Ta70. Although the thickness of nanolamellas varied, there were no significant differences in the RMS roughness between Ta40 and Ta70 ( 3.09 and $2.68 \mathrm{~nm}$ respectively). The nanolamella was observed to be oriented parallel to one another in both Ta40 and Ta70. And the depth of nanolamellas are 2 9 $\mathrm{nm}$, as exhibited from height profiles in Figure 1(c).

(a)
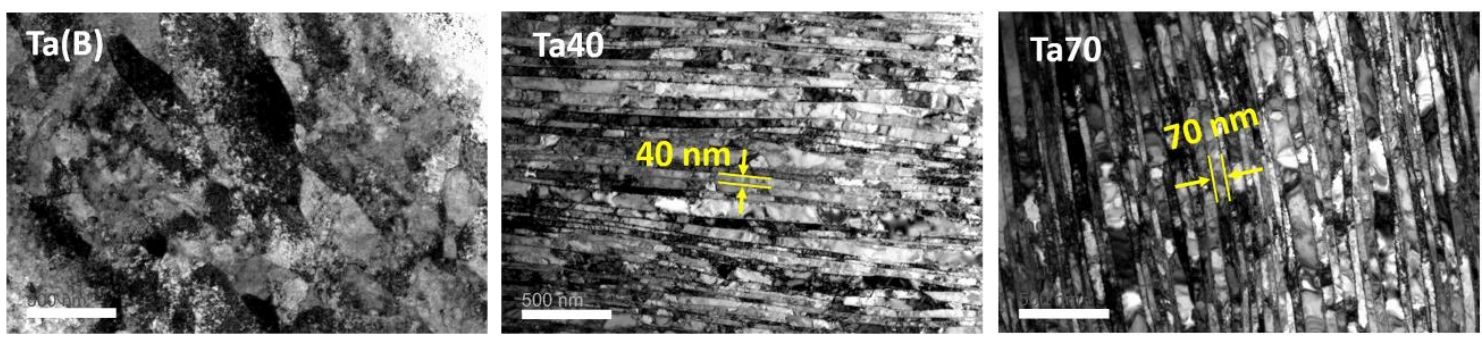
(b)
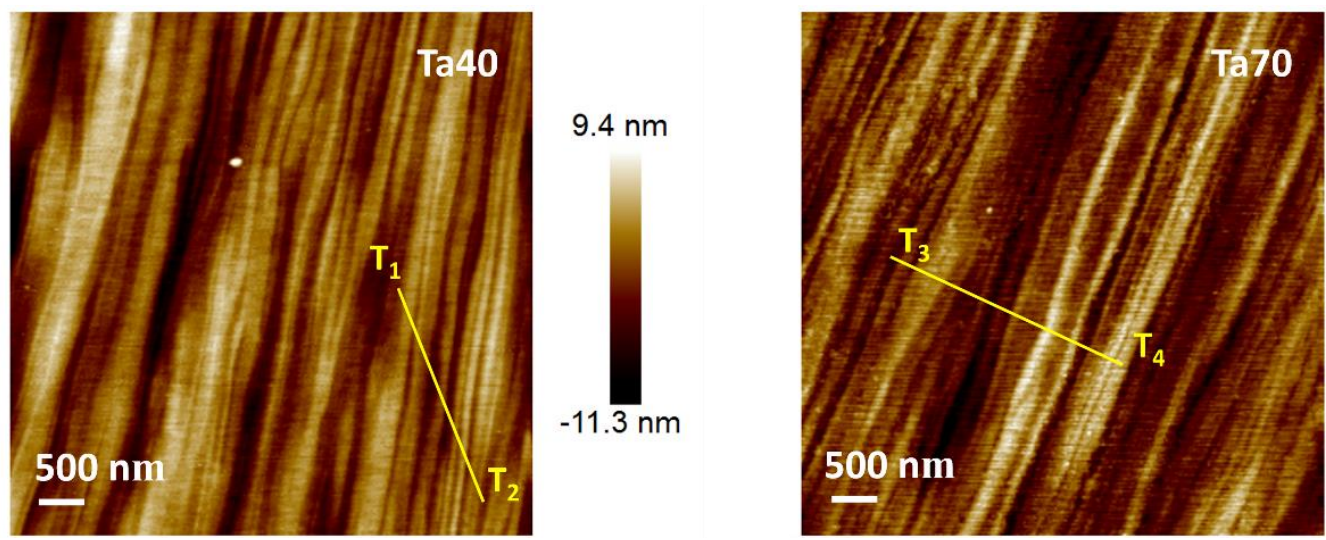

$9.2 \mathrm{~nm}$

$9.4 \mathrm{~nm}$
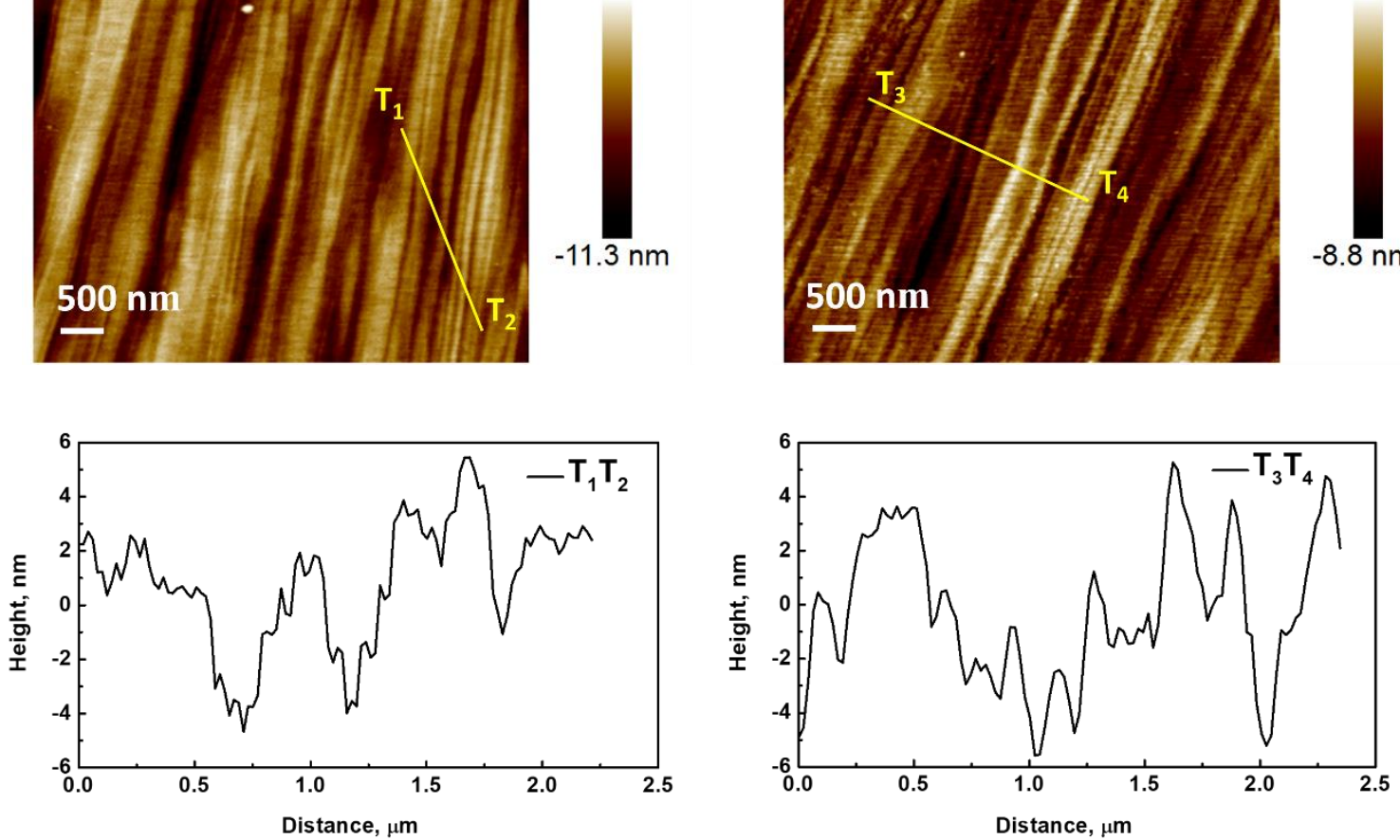

(c)

Figure 1. (a) TEM images of bulk tantalum 'Ta(B)', nanolamellar tantalum 'Ta40' and 'Ta70'.

Scale bars $=500 \mathrm{~nm}$. (b) AFM detailed topographic images and (c) height profiles along lines $\mathrm{T}_{1} \mathrm{~T}_{2}, \mathrm{~T}_{3} \mathrm{~T}_{4}$ in $\mathrm{Ta} 40$ and $\mathrm{Ta} 70$.

Figure 2 shows the X-ray diffraction (XRD) patterns of the bulk $\mathrm{Ta}(\mathrm{Ta}(\mathrm{B}))$, as well as the nanolamellar Ta with lamella wall thicknesses of $\sim 40$ and $70 \mathrm{~nm}$ (Ta40, Ta70). All major diffraction peaks in $\mathrm{Ta}(\mathrm{B})$, Ta40 and Ta70, match the standard peaks of tantalum phase well, ${ }^{41}$ while weak peaks correspond to a Ta(200) plane were observed in Ta40 and Ta70, as compared to that in bulk Ta (see the inset in Figure 2). No peak shift was observed for both bulk and nanolamellar Ta, indicative of no influences on the composition from the repeated rolling process. 


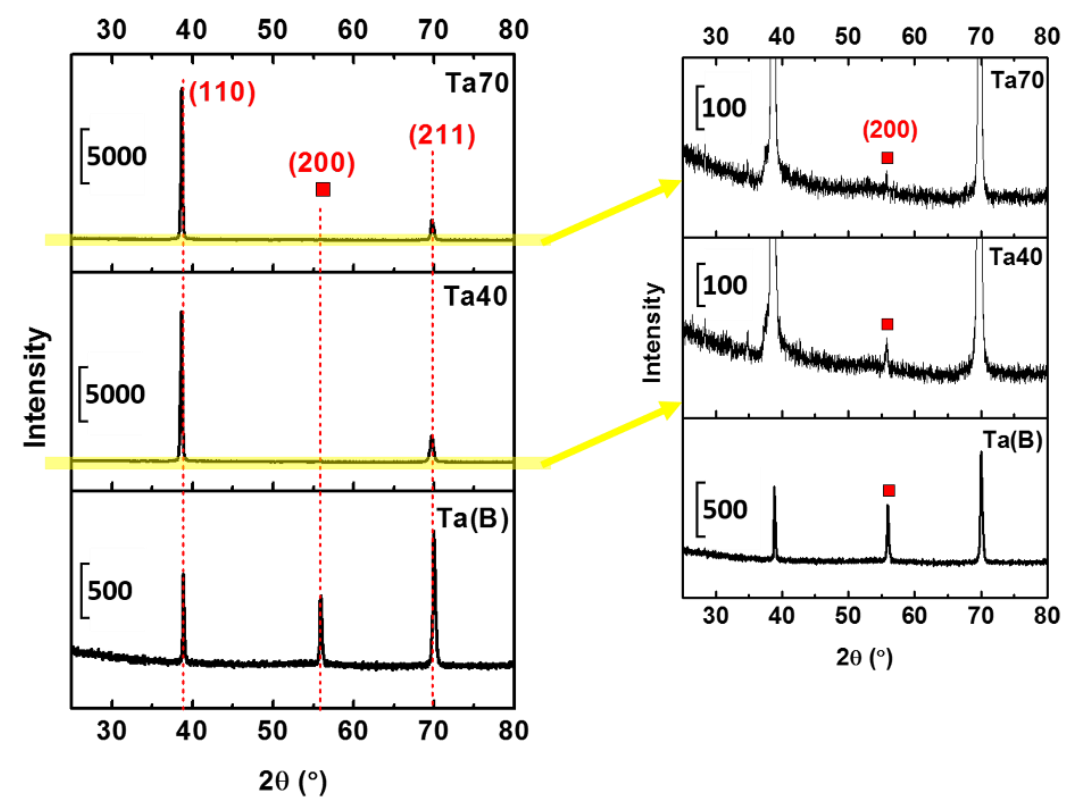

Figure 2. X-ray diffraction patterns detected on bulk tantalum ' $\mathrm{Ta}(\mathrm{B})$ ', and nanolamellar tantalum 'Ta40' and 'Ta70', the inset showing a magnified XRD patterns for $\mathrm{Ta}(200)$ phase.

Surface wettability is a key factor with respect to influencing the cell adhesion and protein adsorption. ${ }^{42,43}$ With a contact angle goniometer, we observed a wettability difference among our bulk $\operatorname{Ta}(\mathrm{B})\left(\right.$ contact angle $\left.\theta=48 \pm 2^{\circ}\right)$ and nanolamellar Ta40 $\left(\theta=87 \pm 2^{\circ}\right)$ and $\operatorname{Ta} 70\left(\theta=74 \pm 3^{\circ}\right)$ surfaces, as shown in Figure 3. As compared to the non-structured $\mathrm{Ta}(\mathrm{B})$, the observed increase in contact angles for Ta40 and Ta70 is due to "air" trapped ${ }^{44}$ in the grooves of nanolamellar surfaces, which decreased the water-surface contact. While Ta40 with a smaller lamella wall thickness exhibited a more 'hydrophobic' propensity, by offering more grooves than Ta70 for trapping air, and thus enlarging the contact angle. Surface hydrophobicity can positively influence the protein adherence through the exclusion of water molecules from the surface. ${ }^{45,46}$ 


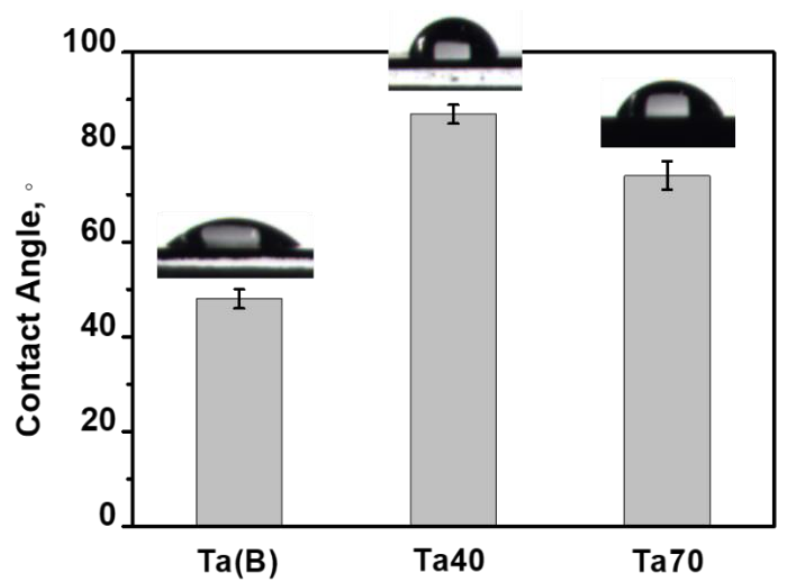

Figure 3. Water contact angles on bulk Ta(B), and nanolamellar Ta40 and Ta70 surfaces.

Protein adsorption. Protein adsorption suggests an important role in regulating the cell attachment to biomaterials. ${ }^{47-49}$ Bovine serum albumin, BSA was found to be able to modulate the proliferation state of the bound cells. ${ }^{49}$ We thus employed the confocal laser scanning microscopy to evaluate the nanolamella effect on the adsorption of the specific proteins, fluorochrome labeling BSA (Figure 4). An obviously more intense fluorescence intensity was observed in Ta40 and Ta70, as compared to the bulk Ta(B), suggesting higher amounts of BSA adsorbed on the nanolamellar surfaces. As expected, the relative 'hydrophobic' Ta40 exhibited the strongest fluorescence intensity, corresponding to a significantly greater adsorption amount of BSA, in an agreement with that a higher and stronger protein adsorption to hydrophobic surfaces compared to hydrophilic surfaces. $^{45,46}$
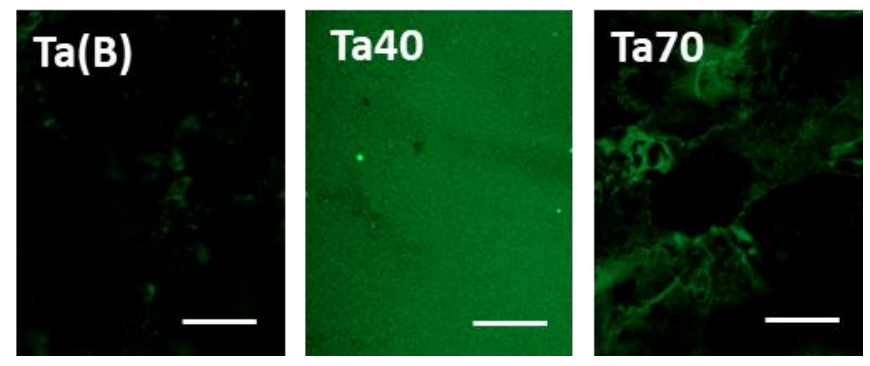

Figure 4. Fluorescence images of the fluorochrome labeling BSA adsorption on bulk Ta(B), 
and nanolamellar Ta40 and Ta70 surfaces. Scale bars $=20 \mu \mathrm{m}$

Cell proliferation assay. Proliferation of cells MC3T3-E1 cultured onto Ta(B), Ta40 and Ta70 surfaces was quantitatively assessed by optical density using CCK-8 assays. Figure 5 shows a comparison of viable cell densities for bulk and nanolamellar Ta samples after 1, 3, 5 and 7 days of culture. An increment in cell numbers for all groups was observed during the initial culture days (day 1 and day 3). This reveals no apparent toxicity and good biocompatibility of Ta(B), Ta40 and Ta70 samples to MC3T3-E1.

After culturing for 1 day, the proliferation of MC3T3-E1 on Ta40 is statistically higher $(\mathrm{p}<0.05)$ than that on $\mathrm{Ta}(\mathrm{B})$ and Ta70. We then observed a similar osteoblast proliferation among the different Ta surfaces by day 3. However, the osteoblast cells proliferated in greater numbers $(\mathrm{p}<0.05)$ on nanolamellar Ta surfaces, i.e., Ta40 and Ta70, in comparison with the non-structured $\mathrm{Ta}(\mathrm{B})$, when the culturing time is extended to 5 and 7 days. The greater number of adherent and proliferated cells on nanolamellar Ta40 and Ta70 surfaces is positively correlated with the more preadsorbed proteins. ${ }^{11,47,48}$ No significant differences of cell numbers were displayed on bulk $\mathrm{Ta}(\mathrm{B})$ by day 5 and day 7, indicative of decreased proliferation. The higher growth rate observed on Ta40 and Ta70 than that on bulk $\mathrm{Ta}(\mathrm{B})$, indicating that nanolamellar structures on Ta is more advantageous to promote MC3T3-E1 (MC cells) proliferation. 


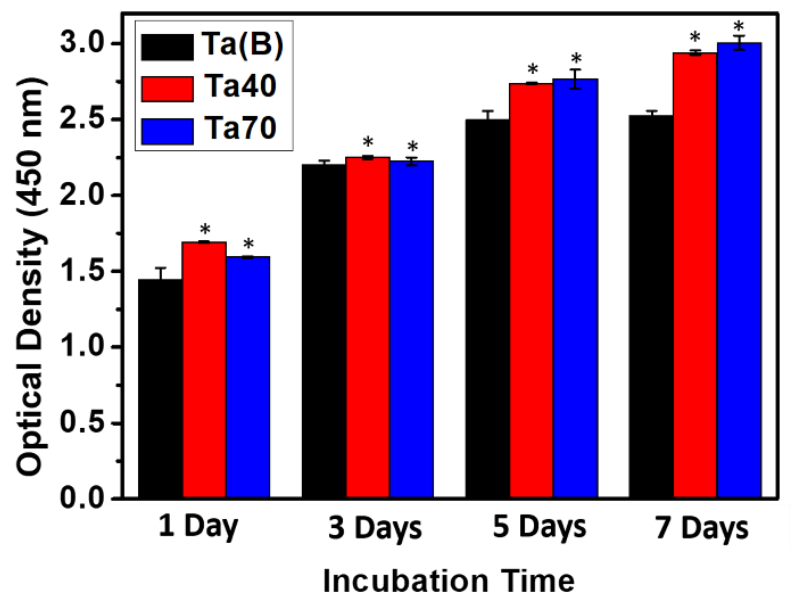

Figure 5. Proliferation of $\mathrm{MC}$ cells seeded on samples $\mathrm{Ta}(\mathrm{B})$, Ta40 and Ta70 measured using CCK-8 assays after $1,3,5$, and 7 days. $*(\mathrm{p}<0.05)$ when compared with $\mathrm{Ta}(\mathrm{B})$.

Fluorescent labeling cells analysis. The proliferation studies were followed up by an investigation of the cell cytoskeleton and assembly of $\beta 1$ integrins. Actin cytoskeletons were labeled to observe the morphology of seeded MC cells for $24 \mathrm{~h}$ on Ta surfaces, as shown in fluorescence images in Figure 6. The cells attached on the bulk Ta(B) surface spread slightly after $24 \mathrm{~h}$ seeding, while Ta40 and Ta70 with nanolamellar structures exhibited a significantly better early cell attachment, with typical fibroblastic morphologies. It is noting that the actin cytoskeleton formation on nanolamellar Ta surfaces were distributed irregularly, in agreement with the isotropically grown cells shown later in SEM observations. This is because, the shallow nanolamellas (less than $12 \mathrm{~nm}$, Figure 1b), cannot control the direction of cell growth. ${ }^{50}$ In contrast to the Ta70 surface with thicker nanolamellas, the MC cells prefer to spread on the Ta40 surface with more and apparent cytoplasmic extensions and filopodial attachments.

$\beta 1$ integrin as a link between the extracellular matrix and cytoskeleton proteins, facilitates cell attaching onto the biomaterial surface ${ }^{51}$ by the regulation of cell migration and intracellular cell adhesion. As shown in Figure 6, the expression of $\beta 1$ integrin was higher in the cells attached 
on nanolamellar Ta40 and Ta70 surfaces as compared to non-structured bulk Ta(B). The higher expression of $\beta 1$ integrin would facilitate the cell attachment and spreading in the early stage, ${ }^{51,52}$ which was confirmed by the SEM-observed higher MC cells adhesion on nanolamellar Ta as shown later in Figure 7(b). The highest $\beta 1$ integrin expression was observed on the Ta40 with a smaller lamella wall thickness, indicating the integrin clustering was more pronounced ${ }^{11}$ on the nanolamellar surface with a thinner lamella.

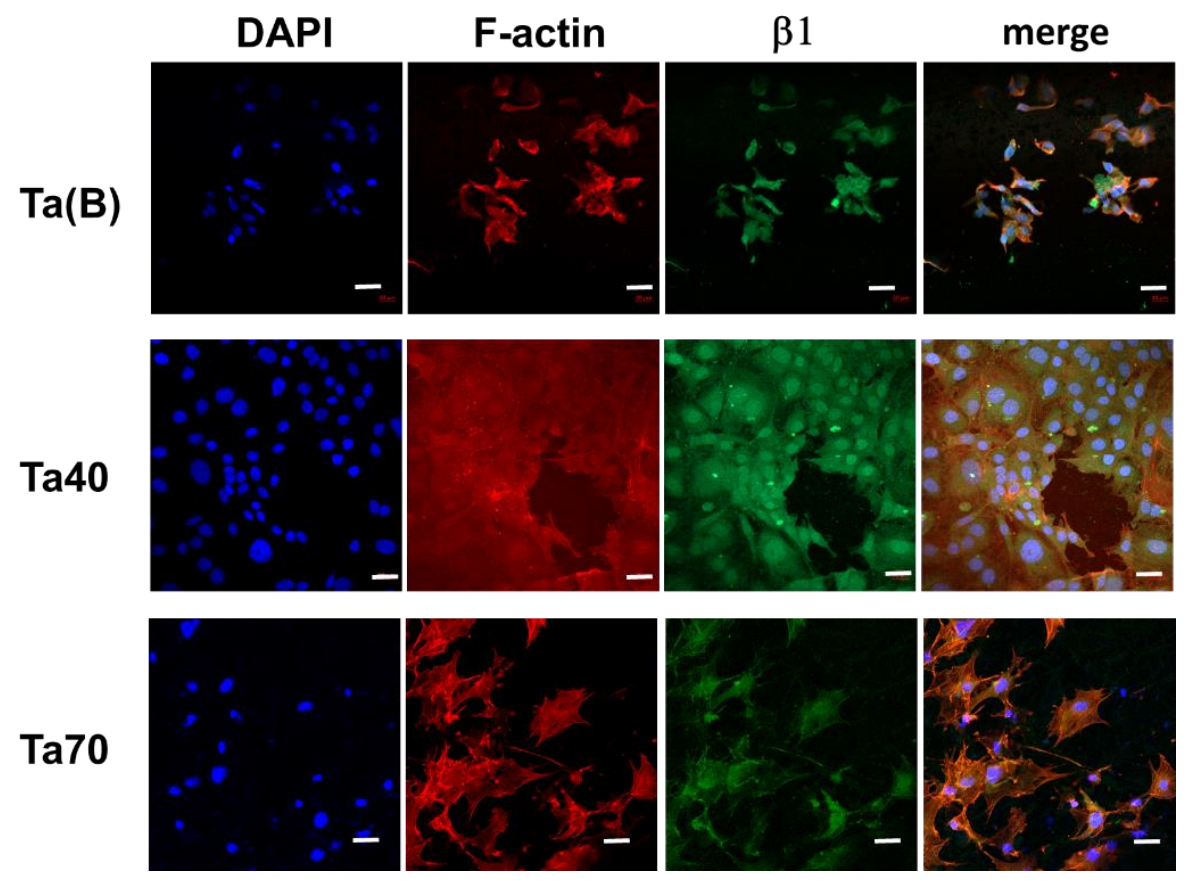

Figure 6. Confocal microscopic images for the nanolamellar structure effect on MC cells attachment after $24 \mathrm{~h}$ seeding, for different surfaces, Ta(B), Ta40, Ta70. Actin filament (cytoskeleton) is stained red, cell nuclei is stained blue, $\beta 1$ integrin is stained green, and the right column represents merged images of the three fluorochromes for each sample. Scale bars=20 $\mu \mathrm{m}$.

ALP activity assay and the growth of seeded MC cells. Alkaline phosphatase (ALP), as an early marker for osteogenic differentiation, was used as an indicator for osteoblastic 
mineralization. ${ }^{53}$ As shown in Figure 7(a), the ALP activity of the osteoblasts were evaluated at days 7 and 14 on Ta(B), Ta40 and Ta70 cultured with MC cells. The ALP activity on bulk Ta(B) at day 7, was lower than those of two nanolamellar Ta surfaces, and the activity on Ta70 was the highest. After 14 days of culture, the ALP activity on all groups has increased higher than that cultured at day 7. We note nanolamellar Ta surfaces exhibited better ALP activity than the bulk one at both day 7 and day 14, demonstrating nanolamellas played a key role on ALP expression. It has been reported that the nanostructure would be strongly favorable for osteogenic differentiation and bone formation ${ }^{54}$. The higher ALP activity observed in our nanolamellar Ta surfaces is probably because, new bones can be induced at nanolamellar structural interfaces by released calcium and phosphate ions during the bone regenerative process. Notably, the activity on thinner Ta40 was enhanced more significantly at day 14, as compared to the Ta70 with thicker nanolamella interfaces. This indicates the positive effect of nanolamellas in osteogenic differentiation is likely to be weakened as the thickness increases.

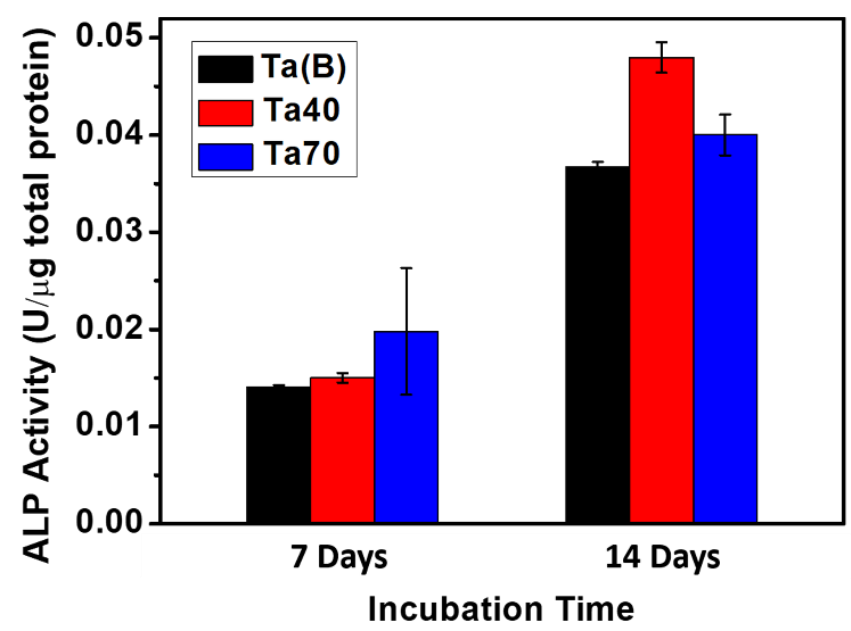

(a) 
(b)
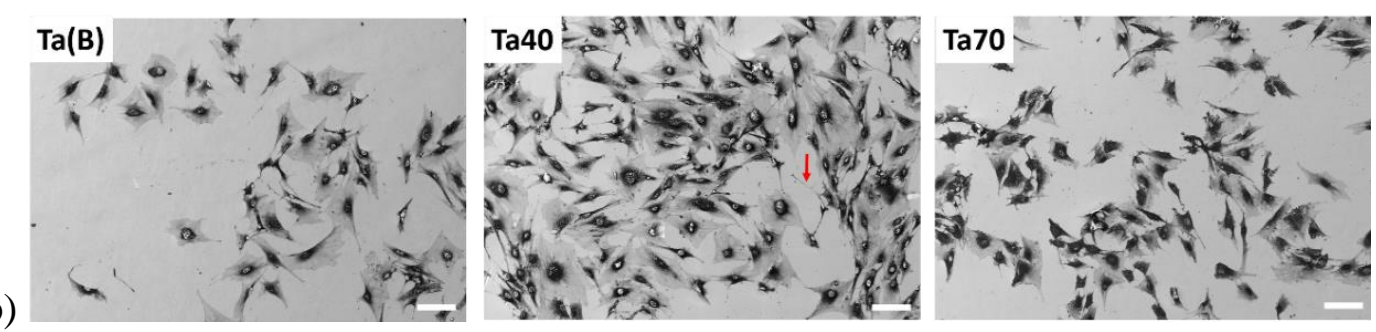

Figure 7. (a) Alkaline phosphatase (ALP) activity of cells cultured on $\mathrm{Ta}(\mathrm{B}), \mathrm{Ta} 40$ and $\mathrm{Ta} 70$ at day 7 and 14, (b) SEM observation of MC cells adhesion on Ta(B), Ta40 and Ta70 after $24 \mathrm{~h}$ incubation. Scale bars $=100 \mu \mathrm{m}$.

The initial adhesion behavior and spreading activity of growing MC cells were monitored by SEM morphological examination. ${ }^{17,24,55}$ As shown in Figure $7(\mathrm{~b})$, after $24 \mathrm{~h}$ of cells culture, it reveals different extensive filopodial activities and network formation on bulk and nanolamellar Ta surfaces. A common speculation is that finger-like filopodia are a cell-sensing and they would be used to detect both chemical and nanotopographical cues. ${ }^{56}$ The association of MC cells with surrounding filopodia were observed, i.e., cells attached, grew well on the Ta surfaces. Nanolamellar Ta40 and Ta70 appeared an increase in both number and length of the filopodia extension in comparison with the bulk $\mathrm{Ta}(\mathrm{B})$ surface. In addition, MC cells grew isotropical on nanolamellar Ta40 and Ta70, because the nanolamellas in both Ta40 and Ta70 are too shallow (less than $12 \mathrm{~nm}$ as shown in Figure 1b) to control the direction of cell growth. ${ }^{50}$ We note the MC cells attached and spread much better on nanolamellar Ta40 than those on Ta70. Occasionally, the observed length of the extension on Ta40 (marked by the red arrow) was even larger than the diameter of the cells. The filopodia extended probably along the valleys between the nanolamellas on Ta40, and cross over to the next nanostructure to form dense networks on the surface. The presence of much more and longer filopodials attached on Ta40 surfaces demonstrates that MC cells are activated more easily by the thinner nanolamellar architecture. This phenomenon was in 
accordance with the experimental evidence reported previously on electrospun fiber meshes that, higher degree of proliferation and cell spreading occurred as the fiber diameter decreased. ${ }^{57}$

Adhesion forces between the MC cell and Ta surfaces. The interaction of osteogenic cells with the implant substrate is crucial to enhance the adhesion and proliferation of osteogenic cells, and consequently promoting new bone formation at an early stage after implantation. The AFM was therefore employed herein to determine adhesion forces between cells and different Ta surfaces, to understand quantitatively at nanoscale, the effect of the cell-Ta interaction strength on the osteoblast adhesion, proliferation and differentiation.
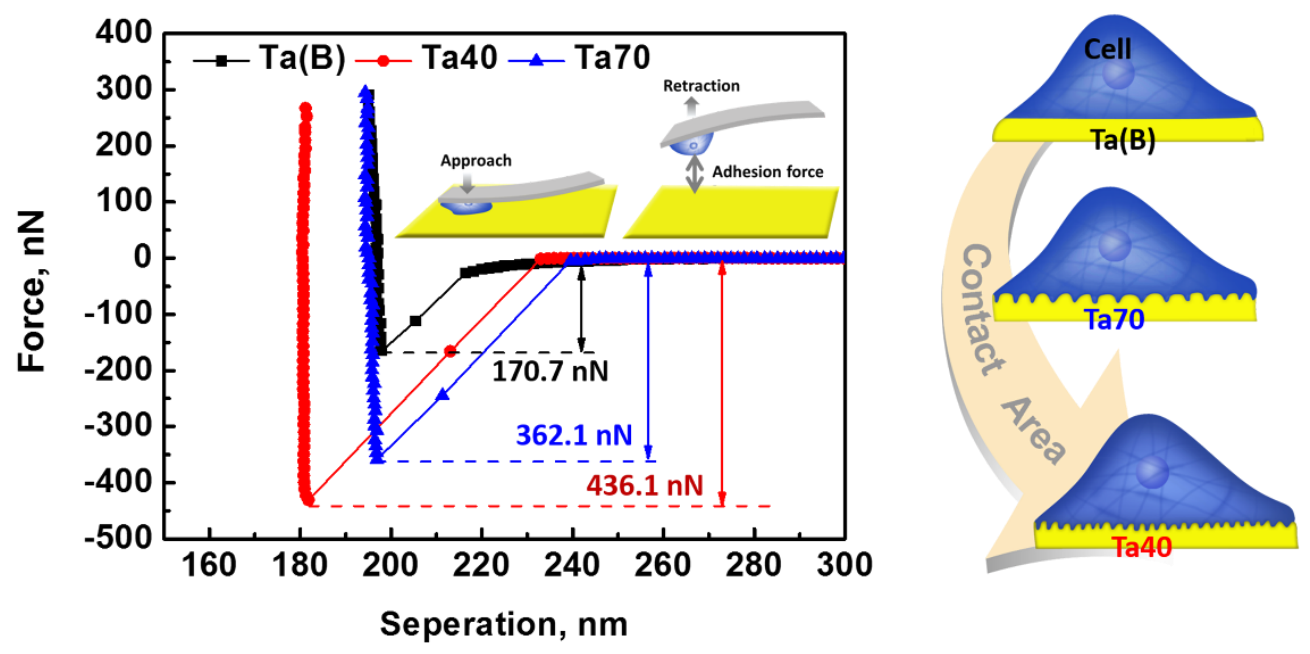

Figure 8. Representative curves of MC cells-cultured AFM probe force during retraction versus the distance of separation on $\mathrm{Ta}(\mathrm{B})$, Ta40 and Ta70 surfaces. Inset in the right: schematic representation of how different Ta surfaces affect cells interaction strength.

Cell attachment onto AFM probes must be realized as the first step. We obtained cellmodified probes by culturing tipless AFM cantilevers in the osteogenic medium for 24 hours. And a cell attached probe was utilized to evaluate cell interactions with different Ta substrates, as 
illustrated in the schematics in the inset of force-distance curves in Figure 8. MC cells exhibit higher adhesion forces towards nanolamellar Ta40 and Ta70 surfaces (436.1, 362.1 nN, respectively), than that towards the bulk $\mathrm{Ta}(\mathrm{B})$ surface $(\sim 170.7 \mathrm{nN})$. As expected, the adhesion force is the strongest between cell-tip and Ta40, which would show positive effects on the activity of cells. The strongest force between MC cells and Ta40, ensures the binding strength of cells with the surface, which resulted in well- attached, stretched, and grown cells on Ta40 as observed in Figures 6 and 7.

We attributed this stronger force on Ta40 to the increase in available contact area of cells with the thinner-nanolamellar surface, as shown in the inset in Figure 8. In contrast, the decreased available contact area of MC cells with thicker-nanolamellar Ta70 and bulk $\mathrm{Ta}(\mathrm{B})$ surfaces, weakens the cell-surface interaction strength. The increased contact area $a^{31,58}$ allows the enhancement of the cell-surface interaction strength on Ta40. In addition, the thinner nanolamellar structures probably favor the diffusion of nutrients, metabolites, and waste products, and this is important for cell proliferation and bone regeneration. ${ }^{59}$ This indicates the thinner nanolamellar structure design is an effective approach, to enhance the osteogenic ability and facilitate the bone regeneration, ${ }^{55}$ by improving the cell-Ta adhesion, osteogenic proliferation and differentiation.

The reported cellular behavior on electrospun fibers indicates that the diameter of fibers significantly influence cell adhesion. The previous findings in electrospun poly-L-lactic acid fibers, ${ }^{31}$ showed that small diameter fibers did not promote extensive cell extension, while larger ones promoted long, directed cell extension. However, the cellular behavior was found to be opposite on electrospun polyethersulfone fibers, i.e., higher adhesion and enhanced migratory ability of cells were revealed on smaller diameter fibers, as compared to the larger ones. ${ }^{57}$ And the packing density of fibers as well as the space between fibers may also influence cell extension. ${ }^{31}$ 
So our next step would be considering thinner lamellas by rolling the bulk ultrafine grained $\mathrm{Ta}(\mathrm{B})$ at cryogenic temperature with liquid helium cooling (much lower temperature than liquid nitrogen), to study if much thinner lamellas can improve the surface osteogenic ability.

\section{CONCLUSIONS}

Equal channel angular pressing with subsequent rolling at liquid $\mathrm{N}_{2}$ and room temperature respectively was employed to fabricate Ta surfaces with nanolamellar structures of different lamella wall thicknesses (40 and $70 \mathrm{~nm}$, i.e., Ta40 and Ta70). Compared to the non-structured bulk $\mathrm{Ta}(\mathrm{B})$, the nanolamellar features on both Ta40 and Ta70 promoted more significantly the osteoblast attachment, spreading, and consequently proliferation and osteogenic differentiation. The cell adhesion and spreading on nanolamellar Ta surfaces in the early stage, were facilitated by the observed greater protein adsorption and higher expression of $\beta 1$ integrin. Ta40 surface with thinner nanolamellas, in particular, achieved the best enhancement effect on cell proliferation and differentiation. This is attributed to the increase in available contact area of cells with Ta40 surface which possesses thinner lamella thickness. The increased contact area would result in the stronger binding strength of cells with the surface, which was confirmed by the strongest adhesion force between cell-attached tip and Ta40 surface measured by AFM. The enhanced cell-surface interaction strength, would thus improve osteoblast adhesion, leading to well- attached, stretched, and grown cells. This strategy to improve cell adhesion and growth by the nanolamellar structure design can open potential applications in implantology or tissue engineering through surface patterning of biomaterial interfaces.

\section{AUTHOR INFORMATION}

\section{Corresponding Authors}

*E-mail: ran@ @just.edu.cn. Phone: +86-25-83403400. Fax: +86-25-83403400 (R.A.) 
*E-mail: zhouxuefeng@ @seu.edu.cn (X.F.Z)

*E-mail: jtwang@njust.edu.cn (J.T.W)

\section{ORCID}

Rong An: 0000-0001-6582-5159

\section{Notes}

The authors declare no competing financial interest.

\section{Author Contributions}

Authors An R. and Fan P. P. contributed equally to this work. All authors have given approval to the final version of the manuscript.

\section{ACKNOWLEDGEMENTS}

We are grateful to the support from the National Natural Science Foundation of China (Grant No. 21606131, 21676137, 31200757, 51520105001), the Fundamental Research Funds for the Central Universities (Grant No. 30918015104) and the Key project (Grant No. T2018107) at Nanjing University of Science and Technology, National Key Basic Research Program (Grant No. 2017YFA0204403), the Chinese Ministry of Science and Technology of China of the National Key Basic Research Program (Grant No. 2012CB932203) and Natural Science Foundation of China-Royal Society International Exchanges Award (IE161237). Zhou X.F. and Zhou M.J. acknowledge the collaborative innovation center of Suzhou Nano Science and Technology (SYG201719). We thank Professor Tao Feng for the access to his polishing machine, and Ms. Qin Tang for her help on improving the schematics illustration.

\section{REFERENCES}


(1) Gentleman, E.; Swain, R. J.; Evans, N. D.; Boonrungsiman, S.; Jell, G.; Ball, M. D.; Shean, T. A. V.; Oyen, M. L.; Porter, A.; Stevens, M. M. Comparative Materials Differences Revealed in Engineered Bone as a Function of Cell-Specific Differentiation. Nat. Mater. 2009, 8, $763-770$.

(2) Chen, H.; Qian, Y.; Xia, Y.; Chen, G.; Dai, Y.; Li, N.; Zhang, F.; Gu, N. Enhanced Osteogenesis of ADSCs by the Synergistic Effect of Aligned Fibers Containing Collagen I. ACS Appl. Mater. Interfaces. 2016, 8, 29289-29297.

(3) Lin, K.; Xia, L.; Gan, J.; Zhang, Z.; Chen, H.; Jiang, X.; Chang, J. Tailoring the Nanostructured Surfaces of Hydroxyapatite Bioceramics to Promote Protein Adsorption, Osteoblast Growth, and Osteogenic Differentiation. ACS Appl. Mater. Interfaces. 2013, 5, 80088017.

(4) Kasemo, B. Biological Surface Science, Surf. Sci. 2002, 500, 656-677.

(5) An, R.; Dong, Y.; Zhu, J.; Rao, C. Adhesion and Friction Forces in Biofouling Attachments to Nanotube- and PEG- Patterned $\mathrm{TiO}_{2}$ Surfaces. Colloid. Surface. B. 2017, 159, 108117.

(6) Swartjes, J. J. T. M.; Veeregowda, D. H.; van der Mei, H. C.; Busscher, H. J.; Sharma, P. K. Normally Oriented Adhesion versus Friction Forces in Bacterial Adhesion to Polymer-Brush Functionalized Surfaces under Fluid Flow. Adv. Funct. Mater. 2014, 24, 44354441.

(7) Findlay, D. M.; Welldon, K.; Atkins, G. J.; Howie, D. W.; Zannettino, A. C. W.; Bobyn, D. The Proliferation and Phenotypic Expression of Human Osteoblasts on Tantalum Metal. Biomaterials 2004, 25, 2215-2227. 
(8) Xia, L.; Lin, K.; Jiang, X.; Xu, Y.; Zhang, M.; Chang, J.; Zhang, Z. Enhanced Osteogenesis through Nano-Structured Surface Design of Macroporous Hydroxyapatite Bioceramic Scaffolds via Activation of ERK and p38 MAPK Signaling Pathways. J. Mater. Chem. B. 2013, 1, 5403-5416.

(9) Dalby, M. J.; Gadegaard, N.; Tare, R.; Andar, A.; Riehle, M. O.; Herzyk, P.; Wilkinson, C. D. W.; Oreffo, R. O. C. The Control of Human Mesenchymal Cell Differentiation Using Nanoscale Symmetry and Disorder. Nat. Mater. 2007, 6, 997-1003.

(10) Anselme, K. Osteoblast Adhesion on Biomaterials. Biomaterials 2000, 21, 667-681.

(11) Dolatshahi-Pirouz, A.; Jensen, T.; Kraft, D. C.; Foss, M.; Kingshott, P.; Hansen, J. L.; Larsen, A. N.; Chevallier, J.; Besenbacher, F. Fibronectin Adsorption, Cell Adhesion, and Proliferation on Nanostructured Tantalum Surfaces. ACS Nano. 2010, 4, 2874-2882.

(12) Maeda, H.; Tomokiyo, A.; Fujii, S.; Wada, N.; Akamine, A. Promise of Periodontal Ligament Stem Cells in Regeneration of Periodontium. Stem. Cell. Res. Ther. 2011, 2, 33.

(13) Gao, H.; Jie, Y. F.; Wang, Z. Q.; Wan, H.; Gong, L.; Lu, R. C.; Xue, Y. K.; Li, D.; Wang, H. Y.; Hao, L. N.; Zhang, Y. Z. B Bioactive Tantalum Metal Prepared by Micro-Arc Oxidation and $\mathrm{NaOH}$ Treatment. J. Mater. Chem. B. 2014, 2, 1216-1224.

(14) Wang, C.; Fan, Z.; Han, Y. Formation and Osteoblast Behavior of HA NanoRod/Fiber Patterned Coatings on Tantalum In Porous and Compact Forms. J. Mater. Chem. B. 2015, 3, 5442-5454.

(15) Levine, B. R.; Sporer, S.; Poggie, R. A.; Della Valle, C. J.; Jacobs, J. J. Experimental and Clinical Performance of Porous Tantalum in Orthopedic Surgery. Biomaterials 2006, 27, 4671-4681. 
(16) Wu, Y. C.; Shaw, S. Y.; Lin, H. R.; Lee, T. M.; Yang, C. Y. Bone Tissue Engineering Evaluation Based on Rat Calvaria Stromal Cells Cultured on Modified PLGA Scaffolds. Biomaterials 2006, 27, 896-904.

(17) Frandsen, C. J.; Brammer, K. S.; Noh, K.; Johnston, G.; Jin, S. Tantalum Coating On $\mathrm{TiO}_{2}$ Nanotubes Induces Superior Rate of Matrix Mineralization and Osteofunctionality in Human Osteoblasts. Mat. Sci. Eng. C-Mater. 2014, 37, 332-341.

(18) Yang, B. C.; Uchida, M.; Kim, H. M.; Zhang, X. D.; Kokubo, T. Preparation of Bioactive Titanium Metal via Anodic Oxidation Treatment. Biomaterials 2004, 25, 1003-1010.

(19) Hall, D. J.; Urban, R. M.; Pourzal, R.; Turner, T. M.; Skipor, A. K.; Jacobs, J. J. Nanoscale Surface Modification by Anodic Oxidation Increased Bone Ingrowth and Reduced Fibrous Tissue in the Porous Coating of Titanium-Alloy Femoral Hip Arthroplasty Implants. $J$. Biomed. Mater. Res. B. 2017, 105, 283-290.

(20) Brodbeck, W. G.; Nakayama, Y.; Matsuda, T.; Colton, E.; Ziats, N. P.; Anderson, J. M. Biomaterial Surface Chemistry Dictates Adherent Monocyte/Macrophage Cytokine Expression in vitro. Cytokine 2002, 18, 311-319.

(21) Chen, S.; Jiang, S. A New Avenue to Nonfouling Materials. Adv. Mater. 2008, 20, $335-338$.

(22) Zhang, Z.; Chen, S.; Jiang, S. Dual-functional Biomimetic Materials: Nonfouling Poly(Carboxybetaine) with Active Functional Groups for Protein Immobilization. Biomacromolecules 2006, 7, 3311-3315.

(23) Nie, F. L.; Zheng, Y. F.; Wang, Y.; Wang, J. T. Microstructures, Mechanical Behavior, Cellular Response, and Hemocompatibility of Bulk Ultrafine-Grained Pure Tantalum. J. Biomed. Mater. Res. B. 2014, 102, 221-230. 
(24) Choi, C.-H.; Hagvall, S. H.; Wu, B. M.; Dunn, J. C. Y.; Beygui, R. E.; Kim, C.-J. Cell Interaction with Three-Dimensional Sharp-Tip Nanotopography. Biomaterials 2007, 28, $1672-1679$.

(25) Wang, P.-Y.; Bennetsen, D. T.; Foss, M.; Ameringer, T.; Thissen, H.; Kingshott, P. Modulation of Human Mesenchymal Stem Cell Behavior on Ordered Tantalum Nanotopographies Fabricated Using Colloidal Lithography and Glancing Angle Deposition. ACS Appl. Mater. Interfaces. 2015, 7, 4979-4989.

(26) Huo, W. T.; Zhao, L. Z.; Yu, S.; Yu, Z. T.; Zhang, P. X.; Zhang, Y. S. Significantly Enhanced Osteoblast Response to Nano-Grained Pure Tantalum, Sci. Rep. 2017, 7, 40868

(27) Yu, C.; Zhuang, J.; Dong, L.; Cheng, K.; Weng, W. Effect of Hierarchical Pore Structure on ALP Expression of MC3T3-E1 Cells on Bioglass Films. Colloid. Surface. B. 2017, $156,213-220$.

(28) Balla, V. K.; Bodhak, S.; Bose, S.; Bandyopadhyay, A. Porous Tantalum Structures For Bone Implants: Fabrication, Mechanical And In Vitro Biological Properties, Acta. Biomater. 2010, 6, 3349-3359.

(29) Hallab, N. J.; Bundy, K. J.; O'Connor, K.; Moses, R. L.; Jacobs, J. J. Evaluation of Metallic and Polymeric Biomaterial Surface Energy and Surface Roughness Characteristics for Directed Cell Adhesion. Tissue. Eng. 2001, 7, 55-71.

(30) Lowery, J. L.; Datta, N.; Rutledge, G. C. Effect of fiber Diameter, Pore Size and Seeding Method on Growth of Human Dermal Fibroblasts in Electrospun Poly( $\varepsilon$-caprolactone) Fibrous Mats. Biomaterials 2010, 31, 491-504. 
(31) Wang, H. B.; Mullins, M. E.; Cregg, J. M.; McCarthy, C. W.; Gilbert, R. J. Varying the Diameter of Aligned Electrospun Fibers Alters Neurite Outgrowth and Schwann Cell Migration. Acta. Biomater. 2010, 6, 2970-2978.

(32) Feng, J.; Zhang, D.; Zhu, M.; Gao, C. Poly(L-lactide) Melt Spun Fiber-Aligned Scaffolds Coated with Collagen or Chitosan for Guiding the Directional Migration of Osteoblasts in vitro. J. Mater. Chem. B. 2017, 5, 5176-5188.

(33) Liu, B.; Chen, L.; Shao, C.; Zhang, F.; Zhou, K.; Cao, J.; Zhang, D. Improved Osteoblasts Growth on Osteomimetic Hydroxyapatite/BaTiO ${ }_{3}$ Composites with Aligned Lamellar Porous Structure. Mat. Sci. Eng. C-Mater. 2016, 61, 8-14.

(34) Xia, Z.; Villa, M. M.; Wei, M. A Biomimetic Collagen-Apatite Scaffold with A Multi-Level Lamellar Structure for Bone Tissue Engineering. J. Mater. Chem. B. 2014, 2, 19982007.

(35) Valiev, R. Z.; Langdon, T. G. Principles of Equal-Channel Angular Pressing as a Processing Tool for Grain Refinement. Prog. Mater. Sci. 2006, 51, 881-981.

(36) Huang, Y.; Langdon, T. G. Advances in Ultrafine-Grained Materials. Mater. Today 2013, 16, 85-93.

(37) Wei, W.; Wang, S. L.; Wei, K. X.; Alexandrov, I. V.; Du, Q. B.; Hu, J. Microstructure and Tensile Properties of $\mathrm{Cu}-\mathrm{Al}$ Alloys Processed by ECAP and Rolling at Cryogenic Temperature. J. Alloy. Compd. 2016, 678, 506-510.

(38) Konkova, T.; Mironov, S.; Korznikov, A.; Semiatin, S. L. Microstructural Response of Pure Copper to Cryogenic Rolling. Acta Mater. 2010, 58, 5262-5273. 
(39) Cheng, M.; Li, C.; Tang, M. X.; Lu, L.; Li, Z.; Luo, S. N. Intragranular Void Formation in Shock-Spalled Tantalum: Mechanisms and Governing Factors. Acta Mater. 2018, $148,38-48$.

(40) Fang, H. H. P.; Chan, K. Y.; Xu, L. C. Quantification of Bacterial Adhesion Forces Using Atomic Force Microscopy (AFM). J. Microbiol. Meth. 2000, 40, 89-97.

(41) Zeng, L. F.; Gao, R.; Fang, Q. F.; Wang, X. P.; Xie, Z. M.; Miao, S.; Hao, T.; Zhang, T. High Strength and Thermal Stability of Bulk $\mathrm{Cu} / \mathrm{Ta}$ Nanolamellar Multilayers Fabricated by Cross Accumulative Roll Bonding. Acta. Mater. 2016, 110, 341-351.

(42) Hasan, A.; Saxena, V.; Pandey, L. M. Surface Functionalization of Ti6Al4V via Self-assembled Monolayers for Improved Protein Adsorption and Fibroblast Adhesion. Langmuir 2018, 34, 3494-3506.

(43) Matsuno, H.; Ohta, T.; Shundo, A.; Fukunaga, Y.; Tanaka, K. Simple Surface Treatment of Cell-Culture Scaffolds with Ultrafine Bubble Water. Langmuir 2014, 30, 1523815243.

(44) Bhushan, B.; Jung, Y. C.; Niemietz, A.; Koch, K. Lotus-Like Biomimetic Hierarchical Structures Developed by the Self-Assembly of Tubular Plant Waxes. Langmuir 2009, $25,1659-1666$.

(45) Hasan, A.; Waibhaw, G.; Pandey, L. M. Conformational and Organizational Insights into Serum Proteins during Competitive Adsorption on Self-Assembled Monolayers. Langmuir 2018, 34, 8178-8194.

(46) Holmberg, M.; Hou, X. Competitive Protein Adsorption-Multilayer Adsorption and Surface Induced Protein Aggregation. Langmuir 2009, 25, 2081-2089. 
Webb, K.; Hlady, V.; Tresco, P. A. Relative Importance of Surface Wettability and Charged Functional Groups on NIH 3T3 Fibroblast Attachment, Spreading, and Cytoskeletal Organization. J. Biomed. Mater. Res. 1998, 41, 422-430.

(48) Ishizaki, T.; Saito, N.; Takai, O. Correlation of Cell Adhesive Behaviors on Superhydrophobic, Superhydrophilic, and Micropatterned Superhydrophobic/Superhydrophilic Surfaces to Their Surface Chemistry. Langmuir 2010, 26, 8147-8154.

(49) Bernards, M. T.; Qin, C.; Jiang, S. MCM-E1 Cell Adhesion to Hydroxyapatite with Adsorbed Bone Sialoprotein, Bone Osteopontin, and Bovine Serum Albumin. Colloid. Surface. B. 2008, 64, 236-247.

(50) Lenhert, S.; Meier, M.-B.; Meyer, U.; Chi, L.; Wiesmann, H. P. Osteoblast Alignment, Elongation and Migration on Grooved Polystyrene Surfaces Patterned by LangmuirBlodgett Lithography. Biomaterials 2005, 26, 563-570.

(51) Qian, Y.; Zhou, X.; Sun, H.; Yang, J.; Chen, Y.; Li, C.; Wang, H.; Xing, T.; Zhang, F.; Gu, N. Biomimetic Domain-Active Electrospun Scaffolds Facilitating Bone Regeneration Synergistically with Antibacterial Efficacy for Bone Defects. ACS Appl. Mater. Interfaces. 2018, $10,3248-3259$.

(52) Gandavarapu, N. R.; Mariner, P. D.; Schwartz, M. P.; Anseth, K. S. Extracellular Matrix Protein Adsorption to Phosphate-Functionalized Gels from Serum Promotes Osteogenic Differentiation of Human Mesenchymal Stem Cells. Acta Biomater. 2013, 9, 4525-4534.

(53) Kanda, Y.; Nishimura, I.; Sato, T.; Katayama, A.; Arano, T.; Ikada, Y.; Yoshinari, M. Dynamic Cultivation With Radial Flow Bioreactor Enhances Proliferation or Differentiation of Rat Bone Marrow Cells by Fibroblast Growth Factor or Osteogenic Differentiation Factor. Regen. Ther. 2016, 5, 17-24. 
H. Three Dimensional Electrospun PCL/PLA Blend Nanofibrous Scaffolds with Significantly Improved Stem Cells Osteogenic Differentiation and Cranial Bone Formation. Biomaterials 2017, $115,115-127$.

(55) Li, Y.; Xiao, Y.; Liu, C. The Horizon of Materiobiology: A Perspective on Material-Guided Cell Behaviors and Tissue Engineering. Chem. Rev. 2017, 117, 4376-4421.

(56) Dalby, M. J.; Riehle, M. O.; Johnstone, H.; Affrossman, S.; Curtis, A. S. G. Investigating the Limits of Filopodial Sensing: A Brief Report Using SEM to Image the Interaction Between 10 nm High Nano-Topography and Fibroblast Filopodia. Cell. Biol. Int. 2004, 28, 229236.

(57) Christopherson, G. T.; Song, H.; Mao, H.-Q. The Influence of Fiber Diameter of Electrospun Substrates on Neural Stem Cell Differentiation and Proliferation. Biomaterials 2009, 30, 556-564.

(58) Mo, X. M.; Xu, C. Y.; Kotaki, M.; Ramakrishna, S. Electrospun P(LLA-CL) Nanofiber: A Biomimetic Extracellular Matrix for Smooth Muscle Cell and Endothelial Cell Proliferation. Biomaterials 2004, 25, 1883-1890.

(59) Leong, M. F.; Rasheed, M. Z.; Lim, T. C.; Chian, K. S. In vitro Cell Infiltration and in vivo Cell Infiltration and Vascularization in a Fibrous, Highly Porous Poly(D,L-lactide) Scaffold Fabricated by Cryogenic Electrospinning Technique. J. Biomed. Mater. Res. A. 2009, 91A, 231-240. 


\section{TOC}

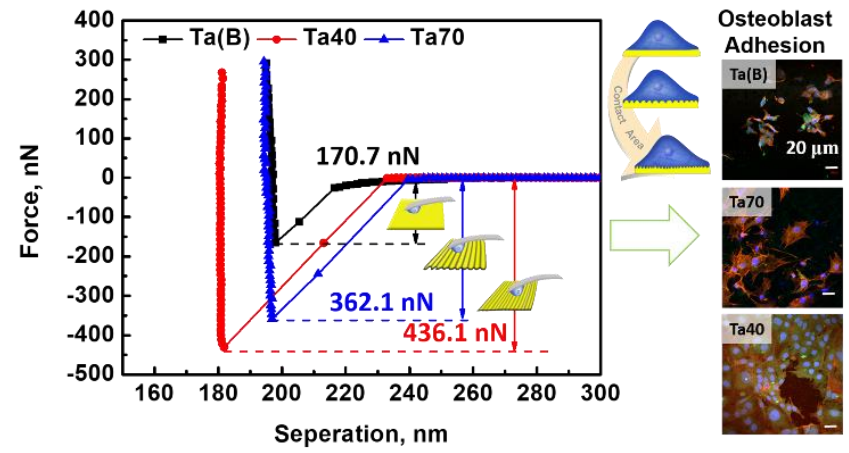

